\title{
Cloud phase identification of Arctic boundary-layer clouds from airborne spectral reflection measurements: test of three approaches
}

\author{
A. Ehrlich ${ }^{1}$, E. Bierwirth ${ }^{1, *}$, M. Wendisch ${ }^{1}$, J.-F. Gayet ${ }^{2}$, G. Mioche ${ }^{2}$, A. Lampert ${ }^{3}$, and J. Heintzenberg ${ }^{4}$ \\ ${ }^{1}$ Johannes Gutenberg-University Mainz, Institute for Atmospheric Physics, Mainz, Germany \\ ${ }^{2}$ Laboratoire de Météorologie Physique (LAMP), Université Blaise Pascal, Aubière Cedex, France \\ ${ }^{3}$ Alfred Wegener Institute for Polar and Marine Research, Potsdam, Germany \\ ${ }^{4}$ Leibniz-Institute for Tropospheric Research, Leipzig, Germany \\ *now at: Laboratory for Atmospheric and Space Physics (LASP), University of Colorado, Boulder, USA
}

Received: 22 July 2008 - Published in Atmos. Chem. Phys. Discuss.: 20 August 2008

Revised: 19 November 2008 - Accepted: 19 November 2008 - Published: 16 December 2008

\begin{abstract}
Arctic boundary-layer clouds were investigated with remote sensing and in situ instruments during the Arctic Study of Tropospheric Aerosol, Clouds and Radiation (ASTAR) campaign in March and April 2007. The clouds formed in a cold air outbreak over the open Greenland Sea. Beside the predominant mixed-phase clouds pure liquid water and ice clouds were observed. Utilizing measurements of solar radiation reflected by the clouds three methods to retrieve the thermodynamic phase of the cloud are introduced and compared. Two ice indices $I_{\mathrm{S}}$ and $I_{\mathrm{P}}$ were obtained by analyzing the spectral pattern of the cloud top reflectance in the near infrared $(1500-1800 \mathrm{~nm}$ wavelength) spectral range which is characterized by ice and water absorption. While $I_{\mathrm{S}}$ analyzes the spectral slope of the reflectance in this wavelength range, $I_{\mathrm{P}}$ utilizes a principle component analysis (PCA) of the spectral reflectance. A third ice index $I_{\mathrm{A}}$ is based on the different side scattering of spherical liquid water particles and nonspherical ice crystals which was recorded in simultaneous measurements of spectral cloud albedo and reflectance.

Radiative transfer simulations show that $I_{\mathrm{S}}, I_{\mathrm{P}}$ and $I_{\mathrm{A}}$ range between 5 to 80,0 to 8 and 1 to 1.25 respectively with lowest values indicating pure liquid water clouds and highest values pure ice clouds. The spectral slope ice in$\operatorname{dex} I_{\mathrm{S}}$ and the PCA ice index $I_{\mathrm{P}}$ are found to be strongly sensitive to the effective diameter of the ice crystals present in the cloud. Therefore, the identification of mixed-phase
\end{abstract}

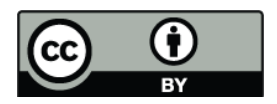

Correspondence to: A. Ehrlich (ehrlichA@uni-mainz.de) clouds requires a priori knowledge of the ice crystal dimension. The reflectance-albedo ice index $I_{\mathrm{A}}$ is mainly dominated by the uppermost cloud layer $(\tau<1.5)$. Therefore, typical boundary-layer mixed-phase clouds with a liquid cloud top layer will be identified as pure liquid water clouds. All three methods were applied to measurements above a cloud field observed during ASTAR 2007. The comparison with independent in situ microphysical measurements shows the ability of the three approaches to identify the ice phase in Arctic boundary-layer clouds.

\section{Introduction}

The impact of clouds on the radiation budget of Arctic regions constitutes a crucial uncertainty in predicting Arctic climate change as reported in the Arctic Climate Impact Assessment (Corell, 2004). In most cases Arctic clouds warm the atmosphere (Intrieri et al., 2002). Due to the high albedo of the snow- or ice-covered surfaces the longwave radiative heating dominates over the solar cooling and thus determines the cloud radiative forcing in the Arctic. Shupe and Intrieri (2004) have shown that low-level clouds are the most important contributors to the Arctic surface radiation budget. Their radiative impact is highly variable and depends on surface albedo, aerosol particles, cloud water content, cloud particle size and cloud thermodynamic phase (Curry et al., 1996; Shupe and Intrieri, 2004).

For example, a low surface albedo in summer leads to a seasonal cooling effect of Arctic clouds (Dong and Mace, 2003). For marine clouds, Freese and Kottmeier (1998) have

Published by Copernicus Publications on behalf of the European Geosciences Union. 
found that the low surface albedo of the ice-free ocean reduces the upwelling radiation above the clouds and thus the cloud albedo by up to $30 \%$ compared to clouds over highly reflecting sea ice. Cloud radiative properties and cloud life cycle are also influenced by the cloud thermodynamic phase (Sun and Shine, 1994; Harrington et al., 1999; Yoshida and Asano, 2005; Ehrlich et al., 2008b). The simulations by Harrington et al. (1999) have shown that the cloud top temperature and the amount of ice nuclei control the conversion of liquid cloud water to solid ice. Cold temperatures and high ice nuclei concentrations lead to a higher ice fraction and a shorter life time of the mixed-phase clouds. Furthermore, Yoshida and Asano (2005) have found that an increasing ice fraction results in a significant increase in the absorptance of mixed-phase clouds in the near infrared wavelength range $(700-2500 \mathrm{~nm})$.

Therefore, in situ measurements and/or remote sensing of the thermodynamic cloud phase are of importance. Parameterizations of the dependence of ice volume fraction (ratio of ice to total water content) on cloud temperature have been obtained from in situ measurements by Boudala et al. (2004); Korolev et al. (2003). However, due to the limitations in time and space in situ measurements can only give a snapshot of the complexity of Arctic clouds (Lawson et al., 2001; Cober et al., 2001; McFarquhar et al., 2007).

Several cloud retrieval algorithms for different satellite sensors provide the cloud phase. Commonly, before retrieving cloud properties a preselection algorithm distinguishes between ice, mixed-phase and liquid water clouds (Key and Intrieri, 2000; King et al., 2004; Kokhanovsky et al., 2006). This phase discrimination is often based on two methods using the brightness temperatures of thermal infrared (IR; $5-50 \mu \mathrm{m})$ channels and the cloud reflectance at channels for near infrared wavelength range (NIR, 700-2500 nm). Further methods are based on radar data (CloudSat, Sassen and Wang, 2008) and polarization measurements, for example using data of the POLarization and Directionality of the Earth's Reflectances instrument (POLDER, Buriez et al., 1997).

The contrast of brightness temperatures measured at two wavelengths is related to the ice volume fraction due to the different emissivity of ice and liquid water at wavelengths larger than $10 \mu \mathrm{m}$. Similarly, the cloud reflectance at NIR wavelengths is affected by the different refractive indices (in particular the imaginary part, i.e. absorption index) of ice and liquid water as demonstrated by Pilewskie and Twomey (1987). Therefore, the ratio of cloud reflectances at two wavelengths can be used to determine the cloud thermodynamic phase (band ratio method). Both methods were compared by Chylek et al. (2006) for the Moderate Resolution Imaging Spectroradiometer (MODIS) showing significant discrepancies between the results of the two methods with a tendency of an overestimation of ice clouds by the band ratio method. The authors suggest to use the ratio of highly resolved NIR spectral bands around 1.5 and
$1.4 \mu \mathrm{m}$. This has successfully been applied by Knap et al. (2002) and Acarreta et al. (2004) for the Airborne Visible and Infrared Imaging Spectrometer (AVIRIS) and the Scanning Imaging Absorption Spectrometer for Atmospheric CHartographY (SCIAMACHY).

In this study we present similar methods of cloud phase identification using airborne measurements of spectral solar cloud reflectance combined with radiative transfer simulations. Three approaches to discriminate the cloud phase are applied and discussed. First results applying these methods have been published in Ehrlich et al. (2008a). The measurements presented here were performed during the Arctic Study of Tropospheric Aerosol, Clouds and Radiation (ASTAR) 2007 campaign. Additional information on cloud phase was obtained from in situ cloud microphysical and airborne lidar measurements.

The instrumentation of the aircraft is described in Sect. 2. The measurements of spectral cloud reflectance and three methods to obtain information on the cloud phase are discussed in Sects. 3 and 4. Subsequently, the three methods are analyzed by sensitivity studies in Sect. 5. Finally, in Sect. 6 the application of the methods is examined by a case study of observations from 7 April 2007.

\section{Instrumentation}

During ASTAR 2007 two aircraft were employed. We report on data from the Polar 2 aircraft, owned by the Alfred Wegener Institute for Polar and Marine Research (AWI), Bremerhaven, Germany. The airborne instrumentation included the Spectral Modular Airborne Radiation measurement sysTem (SMART-Albedometer), in situ instruments such as the Polar Nephelometer, Cloud Particle Imager (CPI), and Particle Measuring System (PMS) Forward Scattering Spectrometer Probe (FSSP-100), and the Airborne Mobile Aerosol Lidar (AMALi).

The SMART-Albedometer was developed at the LeibnizInstitute for Tropospheric Research, Leipzig, Germany as a modular system to measure solar spectral radiation (radiance, irradiance, actinic flux density) from airborne platforms as described, e.g., by Wendisch and Mayer (2003); Wendisch et al. (2004); Jäkel et al. (2005); Bierwirth et al. (2009). The optical inlets for separate detection of upwelling and downwelling radiation are actively leveled to compensate deviations of the aircraft attitude from the horizontal plane (Wendisch et al., 2001). The configuration of the SMARTAlbedometer operated during ASTAR 2007 provides measurements of downwelling and upwelling spectral irradiances $\left(F_{\lambda}^{\downarrow}, F_{\lambda}^{\uparrow}\right)$ simultaneously with upwelling nadir spectral radiance $\left(I_{\lambda}^{\uparrow}\right)$. The downwelling irradiance presented here includes diffuse and direct solar radiation and is measured with respect to a horizontal plane $F_{\lambda}^{\downarrow}=F_{\lambda}^{\downarrow}(\cos \theta)$ with $\theta$ giving the solar zenith angle. 
Two spectrometer systems have been applied to measure $F_{\lambda}^{\downarrow}$ and $I_{\lambda}^{\uparrow}$ at the visible and near infrared wavelengths. The spectrometer systems cover the spectral wavelength range $350-950 \mathrm{~nm}$ and $950-2100 \mathrm{~nm}$ with a spectral resolution (full width at half maximum) of $2-3 \mathrm{~nm}$ and $9-16 \mathrm{~nm}$, respectively. $F_{\lambda}^{\uparrow}$ was measured in the visible part of the spectrum only $(350-950 \mathrm{~nm})$. The optical inlets for the irradiance measurements (constructed by the Bay Area Environmental Research Institute, CA, USA) are designed as integrating spheres made of Spectralon reflectance material (Crowther, 1997). Sealed with a quartz dome, the Spectralon integrating sphere provides an almost wavelength-independent photon collection efficiency. To measure $I_{\lambda}^{\uparrow}$ a set of new optical inlets for radiance measurements has been constructed. The entrance optics of the radiance optical inlet is based on a Zeiss collimator lens (BK 7 glass) with a focal length of $31.6 \mathrm{~mm}$. The collimator is mounted within a cylindrical housing that reduces stray light. Two apertures at both ends of the housing define the angle of view. Laboratory measurements and ray tracing simulations found an angle of view of $2.1^{\circ}$. The outer aperture is covered by BK 7 glass providing vacuum conditions inside the tube and protection against condensation during changes of the external temperature conditions.

The in situ measurements of cloud microphysical properties include particle number size distribution in the size range of 3-27 $\mu \mathrm{m}$ for the FSSP and $23-2300 \mu \mathrm{m}$ for the CPI, extinction coefficient, ice and liquid water content, effective diameter, scattering phase function and the asymmetry parameter, a measure for the anisotropy of the scattering phase function. The instruments, data retrieval and measurement uncertainties are described by Gayet et al. (2007).

Additional independent information on the cloud phase was provided by the depolarization measurements of AMALi which is a two-wavelength ( $532 \mathrm{~nm}$ and $355 \mathrm{~nm}$ ) backscatter lidar with depolarization measurements at $532 \mathrm{~nm}$ wavelength. AMALi was installed in nadir-looking configuration. The vertical resolution was $7.5 \mathrm{~m}$; the minimum horizontal resolution was about $900 \mathrm{~m}$. Further details of AMALi are described in Stachlewska et al. (2004).

\section{Measurements}

\subsection{Synoptic situation}

We concentrate on a special period during ASTAR 2007 (79 April) which was characterized by a cold air outbreak. The northerly winds initiated extended boundary-layer cloud fields over the open Greenland Sea as shown by the MODIS satellite image in Fig. 1. The convection above the relatively warm open sea maintained the coexistence of ice and liquid water particles in the clouds. Detailed investigations on the self-maintaining dynamics of the mixed-phase clouds are described by Harrington et al. (1999); Fridlind et al. (2007);

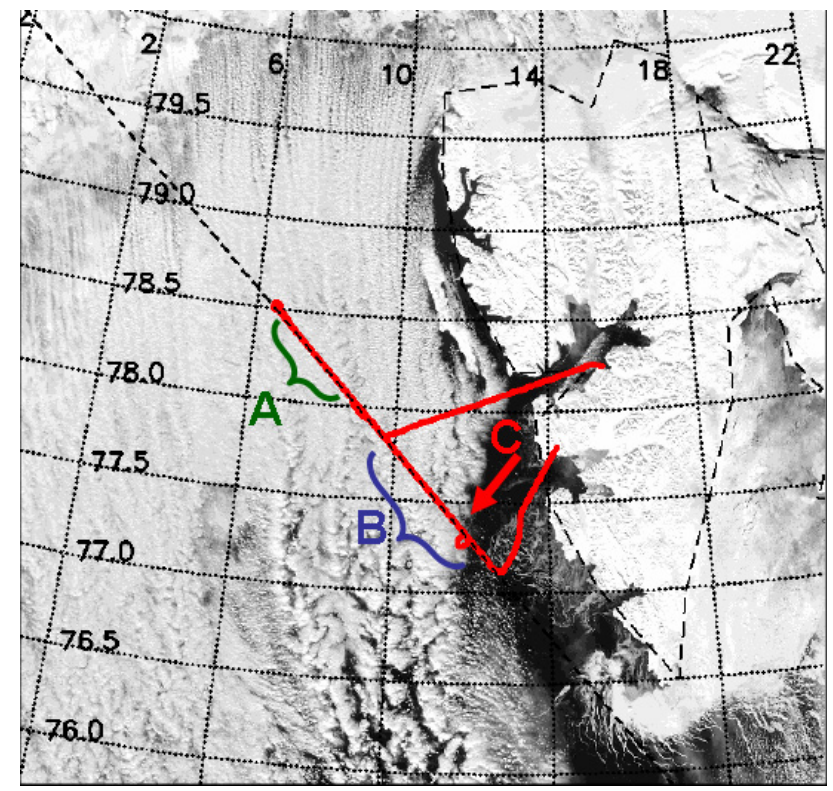

Fig. 1. MODIS satellite image of 7 April 2007 overlaid with the flight track of Polar 2 aircraft (red line) along the CALIPSO overpass (dashed black line). The numbers give the latitude (North) and longitude (East of Greenwich). Flight sections where measurements are analyzed are marked with labels A, B and C. At A a mixed-phase cloud was sampled by both in situ instruments and the SMART-Albedometer, at $\mathrm{C}$ a pure ice cloud was observed with the SMART-Albedometer only (cf. Sect. 3). The flight section B is analyzed with regard to cloud thermodynamic phase in Sect. 6.

Morrison et al. (2008). In addition to the predominating mixed-phase clouds, pure ice and pure liquid water clouds were observed during this period of ASTAR 2007 providing the possibility to test cloud phase identification methods.

\subsection{In situ measurements}

In situ measurements have been obtained from a total of 16 vertical profiles flown between 7-9 April. Except for two profiles taken at the edge of the cloud fields where pure ice clouds were observed, the in situ measurements generally show the typical structure of the prevailing mixedphase clouds with a cloud top layer consisting of liquid water and precipitating ice crystals below. Based on in situ data, the particle phase was determined from the combination of asymmetry parameter and particle concentration measurements. The asymmetry parameter is significantly lower for nonspherical ice crystals than for spherical liquid water particles (e.g., Gerber et al., 2000; Garrett et al., 2001). As an approximation the FSSP size range (3-27 $\mu \mathrm{m})$ is defined to measure liquid water particles whereas the CPI $(23-2300 \mu \mathrm{m})$ is used to determine the size distribution of large ice crystals. An analysis of the combined particle concentration and asymmetry parameter measurements (not shown here) confirms, that this assumption works sufficiently 


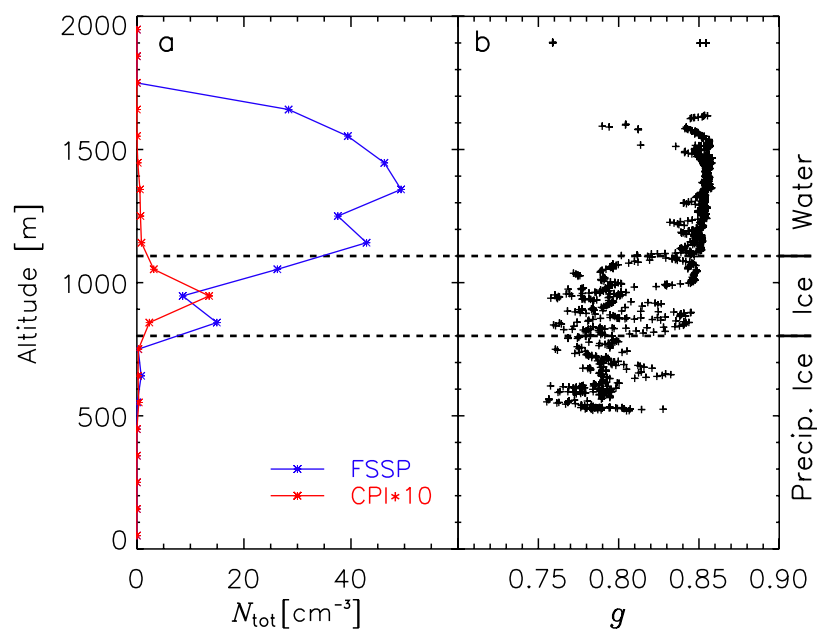

Fig. 2. Profiles of microphysical measurements on 7 April 2007. Total particle concentrations $N_{\text {tot }}$ measured by FSSP and CPI are given in panel a. The asymmetry parameter $g$ obtained from the Polar Nephelometer is shown in panel $b$.

well for the mixed-phase clouds encountered during ASTAR 2007.

A typical profile of measured particle concentration and asymmetry parameter obtained on 7 April between $78.0^{\circ} \mathrm{N}$ and $78.5^{\circ} \mathrm{N}$ (cp. Fig. 1 label A) is presented in Fig. 2. The FSSP indicated particle concentrations up to $N_{\text {tot }}=50 \mathrm{~cm}^{-3}$ between 1000-1700 $\mathrm{m}$ altitude. In the same layers the asymmetry parameter measured by the Polar Nephelometer, was about 0.85 which is a typical value for liquid water droplets (e.g., Gerber et al., 2000; Garrett et al., 2001). A thin layer dominated by ice crystals was found between $800 \mathrm{~m}$ and $1100 \mathrm{~m}$, indicated by lower asymmetry parameters. In this layer the CPI measured particle concentrations of up to $N_{\text {tot }}=1.5 \mathrm{~cm}^{-3}$ with maximum particle dimensions of up to $1000 \mu \mathrm{m}$. Below this layer, precipitating large ice particles were observed down to $500 \mathrm{~m}$ by visual observation on board the aircraft and from in situ measurements indicating a low particle concentration (CPI and FSSP) and a low asymmetry parameter measured by the Polar Nephelometer.

The profile of asymmetry parameter presented in Fig. $2 b$ shows a distinct transition between high values related to liquid water droplets and low values related to ice crystals. Only a few measurements show intermediate values. As Garrett et al. (2001) have shown the asymmetry parameter measured in Arctic stratus changes linearly from 0.86 to 0.76 depending on the fractional number of particles in the cloud that are ice rather than liquid. Therefore, the measurements presented in Fig. $2 b$ reveal that liquid water droplets are dominant in the upper cloud layer and ice crystals characterize the optical properties of the lower cloud layers.
The mean effective diameters of ice crystals and liquid water particles averaged over the in situ measurements of the entire cloud amounts to $(85 \pm 37) \mu \mathrm{m}$ for ice crystals (CPI) and $(15 \pm 5) \mu \mathrm{m}$ for liquid water particles (FSSP). The cloud optical thickness estimated from the measured extinction coefficients from the FSSP and CPI was about 15-20.

\subsection{Airborne lidar measurements}

The laser of the AMALi lidar did not completely penetrate the optically thick clouds. However, AMALi did identify a liquid water layer at cloud top by the depolarization signal. Although multiple scattering in the liquid water layer generated high depolarization values, comparable to the depolarization signal of ice crystals, the detailed analysis of the lidar profiles averaged over $15 \mathrm{~s}$ reveals differences in the vertical pattern of the depolarization. The depolarization related to multiple scattering of liquid water particles increases slowly with cloud depth whereas nonspherical ice crystals result in an instantaneous increase of the depolarization $(\mathrm{Hu}$ et al., 2007). From this analysis the precipitating ice below the clouds was identified in several cloud gaps.

\subsection{Cloud top reflectance}

Spectral cloud top reflectances $R$ were calculated from the SMART-Albedometer radiance and irradiance measurements,

$R_{\lambda}=\pi \cdot I_{\lambda}^{\uparrow} / F_{\lambda}^{\downarrow}$.

Beside the typical mixed-phase clouds also pure ice and pure liquid water clouds were observed during ASTAR 2007. Cloud top reflectances for exemplary samples of all three measured cloud types are shown in Fig. 3a. The mixedphase and ice clouds were observed during the first flight on 7 April as indicated by the labels A and C in Fig. 1. Measured microphysical properties of the mixed-phase cloud are discussed in Sect. 3.2. The water cloud was sampled during a second flight on 7 April between $75.4^{\circ} \mathrm{N}, 11.5^{\circ} \mathrm{E}$ and $75.8^{\circ} \mathrm{N}, 11.8^{\circ} \mathrm{E}$. All measurements shown here are averaged over the time period the cloud was sampled (mixed-phase cloud $18 \mathrm{~min}$, water cloud $8 \mathrm{~min}$ and ice cloud $2 \mathrm{~min}$ ). Especially the liquid water cloud shows differences of $R_{\lambda}$ in the wavelength range between $500 \mathrm{~nm}$ and $1300 \mathrm{~nm}$ as shown in Fig. 3a. These differences result from different cloud optical thickness $\tau$. We retrieved $\tau$ for the clouds presented here by applying standard retrieval techniques (Nakajima and King, 1990). The mixed-phase cloud assumed as liquid water cloud for the retrieval has a $\tau$ of 12 , while for the ice and pure liquid water cloud $\tau=4$ and $\tau=15$ was found, respectively.

In the wavelength range $1450-1750 \mathrm{~nm}$ where $R_{\lambda}$ depends less of $\tau$ the cloud top reflectances reveal significant differences in the spectral pattern. These differences are caused by the contrast in the imaginary part $n_{\mathrm{i}}$ of the refractive index (absorption index) of ice and liquid water shown in Fig. 3b. 


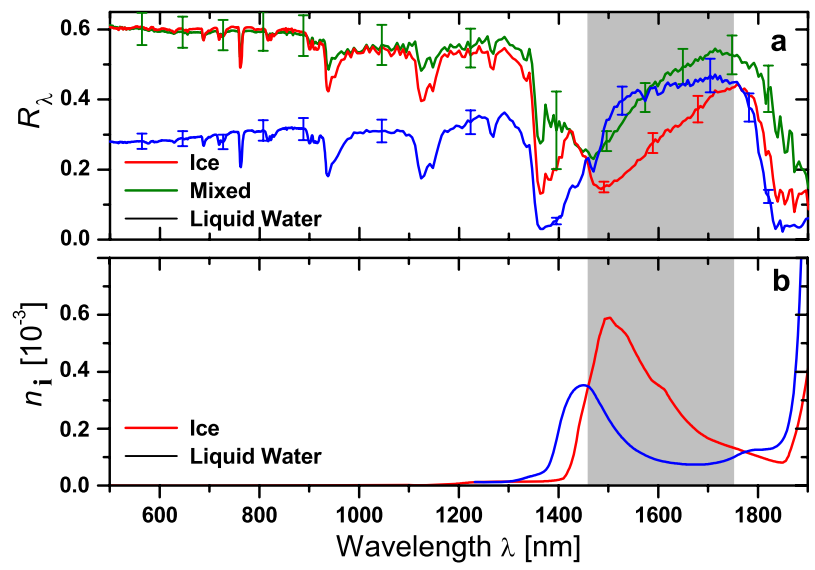

Fig. 3. Examples of measured cloud top reflectance $R_{\lambda}$ (7 April 2007) over a pure ice cloud $(\tau=12)$, pure liquid water cloud ( $\tau=4)$ and mixed-phase cloud $(\tau=15)$ are given in panel a. Error bars indicate the measurement uncertainty of the reflectance measurements. Panel b shows the imaginary part $n_{\mathrm{i}}$ of the refractive index for ice and liquid water.

Of all clouds, pure liquid water clouds show the highest $R_{\lambda}$ values at $1500 \mathrm{~nm}$ where the difference of ice and liquid water absorption is maximum. The slope of the reflectance between $1500 \mathrm{~nm}$ and $1750 \mathrm{~nm}$ is small for liquid water clouds and larger for pure ice clouds. These differences in the spectral pattern of $R_{\lambda}$ can be used to remotely discriminate the cloud phase.

The thermodynamic phase of the ice and mixed-phase clouds presented here has been verified independently by the in situ measurements as described in Sect. 3.2. The ice cloud is investigated in a case study described in Sect. 6.

\section{Definition of ice indices: three approaches}

To define three ice indices characterizing the cloud thermodynamic phase and to evaluate their sensitivity to cloud optical properties we have performed radiative transfer simulations for pre-defined pure ice and pure liquid water boundary-layer clouds of varying optical thickness $(\tau=2 / 4 / 6 / 8 / 10 / 12 / 14 / 16 / 18 / 20)$ and effective diameter $D_{\text {eff. }}$ For liquid water clouds the effective diameter was varied to $8 / 10 / 14 / 20 / 26 \mu \mathrm{m}$ corresponding to the range reported by Miles et al. (2000) for marine stratocumulus clouds. The ice clouds have been modeled for the range of effective diameter observed during ASTAR 2007 $(30 / 60 / 90 / 120 / 150 \mu \mathrm{m})$.

The spectral solar radiative transfer simulations are performed with the libRadtran (Library for Radiative transfer) code by Mayer and Kylling (2005) for the wavelength range from $300 \mathrm{~nm}$ to $2200 \mathrm{~nm}$ adapted to the spectral resolution of the SMART-Albedometer. The discrete ordinate solver DISORT version 2.0 by Stamnes et al. (1988) is applied.

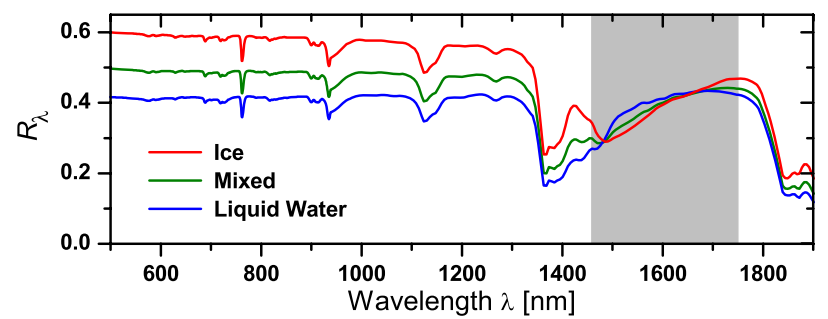

Fig. 4. Examples of simulations of cloud top reflectance $R_{\lambda}$ for pure ice, pure liquid water and mixed-phase clouds with optical thickness of 12 .

The meteorological input (profiles of static air temperature, relative humidity and static air pressure) is obtained from a radio sounding at Ny Ålesund/Svalbard (7 April 2004, 11:00 UTC). Corresponding to the observed marine clouds, the spectral surface albedo is represented by measurements above sea water obtained during ASTAR 2007.

For the radiative transfer simulations a stratiform cloud layer was situated between $750 \mathrm{~m}$ and $1750 \mathrm{~m}$ altitude above the sea surface. The spectral cloud optical properties (extinction coefficient, single scattering albedo and scattering phase function) have been calculated from optical properties of the individual cloud particles. Mie theory is applied for liquid water droplets. For the ice particles column-shaped ice crystals have been assumed. The optical properties of columns have been provided by Yang and Liou (1996). For the simulations presented here the choice of the particle shape is of less importance. With regard to the wavelength range where ice absorption occurs, the predetermined effective diameter of the cloud particles characterizes the absorption independent of the particle shape. For the reflectance at visible wavelengths the scattering phase function of the ice crystals is crucial. However, the part of the scattering phase function relevant for the solar zenith angles observed during ASTAR 2007 is similar for different ice crystal shapes as shown below in Sect. 4.3 and Fig. 8.

Results of the radiative transfer simulations for clouds comparable to the observed ice, liquid water and mixedphase clouds $(\tau=12)$ are given in Fig. 4. To illustrate the spectral differences between $1450 \mathrm{~nm}$ and $1750 \mathrm{~nm}$ the effective diameter of the ice crystals $(20 \mu \mathrm{m})$ and liquid water droplets $(10 \mu \mathrm{m})$ used in the simulations has been chosen to yield a similar magnitude of $R_{1600}$. The mixed-phase cloud was simulated as a single-layer homogeneous mixed cloud with an ice volume fraction of 0.5. The simulations of $R_{\lambda}$ show a similar spectral pattern in the wavelength range $1450-1750 \mathrm{~nm}$ compared to the measurements of the three cloud types (Fig. 3a) with the steepest slope observed for the ice cloud. For wavelengths shorter than $1300 \mathrm{~nm}, R_{\lambda}$ differs in the simulations because of the different scattering phase functions of ice (nonspherical shape) and liquid water particles (spherical shape). 


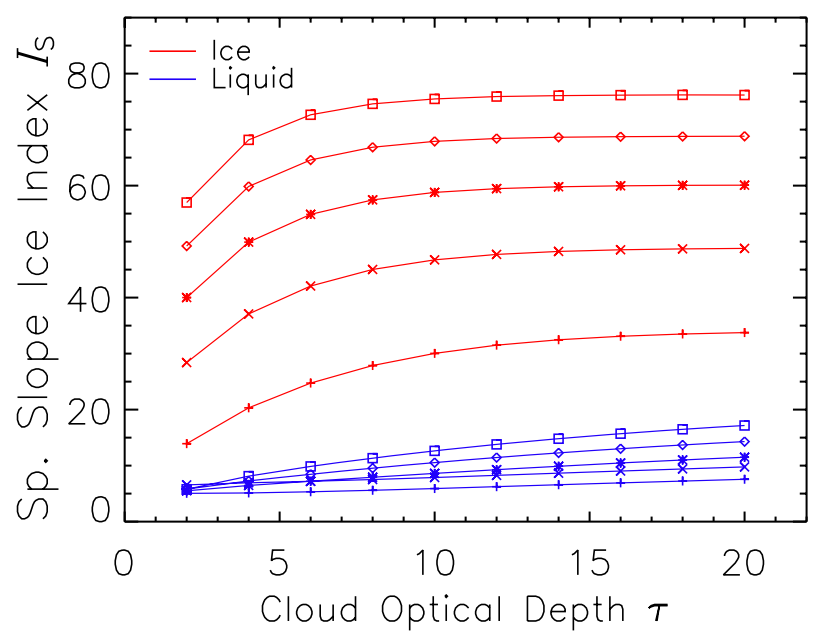

Fig. 5. Spectral slope ice index $I_{S}$ calculated from simulations of pure ice clouds (red) and pure liquid water clouds (blue). The different $D_{\text {eff }}$ are marked by different symbols, plus $\left(D_{\text {eff }}=30 / 8 \mu \mathrm{m}\right)$, cross $\left(D_{\text {eff }}=60 / 12 \mu \mathrm{m}\right), \operatorname{star}\left(D_{\text {eff }}=90 / 16 \mu \mathrm{m}\right)$, diamond $\left(D_{\text {eff }}=120 / 20 \mu \mathrm{m}\right)$, square $\left(D_{\text {eff }}=150 / 26 \mu \mathrm{m}\right)$.

The characteristics of the reflectance spectra are used in the following three approaches to retrieve the cloud phase from the measurements. A known two-wavelengths approach (Sect. 4.1) and a principle component analysis (Sect. 4.2) was applied. A third approach used the combined albedo and reflectance measurements to obtain information on the cloud phase (Sect. 4.3) .

\subsection{Spectral slope ice index}

The spectral slope of the cloud reflectance between $1640 \mathrm{~nm}$ and $1700 \mathrm{~nm}$ has been used to identify the cloud phase with AVIRIS by Knap et al. (2002). The dimensionless ice index, defined as

$$
I_{\mathrm{S}}^{\mathrm{Knap}}=\frac{R_{1700}-R_{1640}}{R_{1640}} \cdot 100,
$$

vanishes for pure liquid water clouds and reaches values of up to 30 for pure ice clouds. For SCIAMACHY Acarreta et al. (2004) have increased the wavelength range used for determination of the spectral slope to $1550-1670 \mathrm{~nm}$. The spectral slope is calculated by linear regression excluding the absorption bands of $\mathrm{CO}_{2}(1560-1580 \mathrm{~nm}$ and $1595-1610 \mathrm{~nm})$. Ice indices calculated this way range between 10 for liquid water clouds and 50 for ice clouds.

The wavelength range used by Acarreta et al. (2004) was limited to $1670 \mathrm{~nm}$ due to technical characteristics of SCIAMACHY with a change of the spectral resolution at $1670 \mathrm{~nm}$. For our measurements with the SMART-Albedometer the
Table 1. Ice indices $I_{\mathrm{S}}, I_{\mathrm{P}}$ and $I_{\mathrm{A}}$ calculated for the observed clouds presented in Fig. 3a.

\begin{tabular}{cccc}
\hline & liquid water & mixed & ice \\
\hline$I_{\mathrm{S}}$ & 8.8 & 29.8 & 57.0 \\
$I_{\mathrm{P}}$ & 0.1 & 2.3 & 5.0 \\
$I_{\mathrm{A}}$ & $*$ & 1.16 & 1.36 \\
\hline
\end{tabular}

definition of ice index $I_{\mathrm{S}}$ is extended to the wavelength range between $\lambda_{a}=1550 \mathrm{~nm}$ and $\lambda_{b}=1700 \mathrm{~nm}$,

$I_{\mathrm{S}}=\frac{100}{R_{1640}}\left[\frac{\mathrm{d} R_{\lambda}}{\mathrm{d} \lambda}\right]_{\left[\lambda_{a}, \lambda_{b}\right]}$

This is the maximum wavelength range where water vapor absorption does not contribute significantly to the measured signal. To reduce the impact of noise from the individual wavelength channels the slope of $R_{\lambda}$ was calculated by linear regression.

The ice indices $I_{\mathrm{S}}$ calculated from the three cloud cases presented in Fig. 3a are given in Table 1. The values range from 8.8 for the liquid water cloud to 57 for the ice cloud with the mixed-phase cloud in-between. These significant differences in $I_{\mathrm{S}}$ confirm that the three observed clouds (pure ice, pure liquid water and mixed-phase) can be distinguished with this method. IS calculated from the simulated ice and liquid water clouds is shown in Fig. 5. Typical values for liquid water clouds range between $I_{\mathrm{S}}=5$ and $I_{\mathrm{S}}=15$. Ice clouds show a higher variability of $I_{\mathrm{S}}$ with values of up to 80 .

\subsection{PCA ice index}

Principle component analysis (PCA) provides a powerful tool to understand the variations in a multivariate data set (Pearson, 1901). The transformation of the original data into a set of principle components compresses the information given by the multivariate data to a few principle components. Analyzing spectral atmospheric radiation measurements the obtained principle components are correlated with physical processes like molecular scattering, trace gas absorption or aerosol interaction (Rabbette and Pilewskie, 2001). We utilize PCA to extract the ice and liquid water absorption signature in measurements and simulations of the spectral cloud top reflectance.

PCA was applied separately on the simulated pure ice and pure liquid water boundary-layer clouds introduced above. For the simulations all effective diameters are taken into account for the PCA, providing a set of 50 different ice and liquid water clouds. The simulated cloud top reflectance was normalized by $R_{860}$ to eliminate the impact of cloud optical thickness. To focus on the ice and liquid water absorption signature only, the wavelength range between $\lambda_{1}=1500 \mathrm{~nm}$ and $\lambda_{2}=1800 \mathrm{~nm}$ was considered for the calculations. Finally, the principle components $P C_{i}$ are calculated 


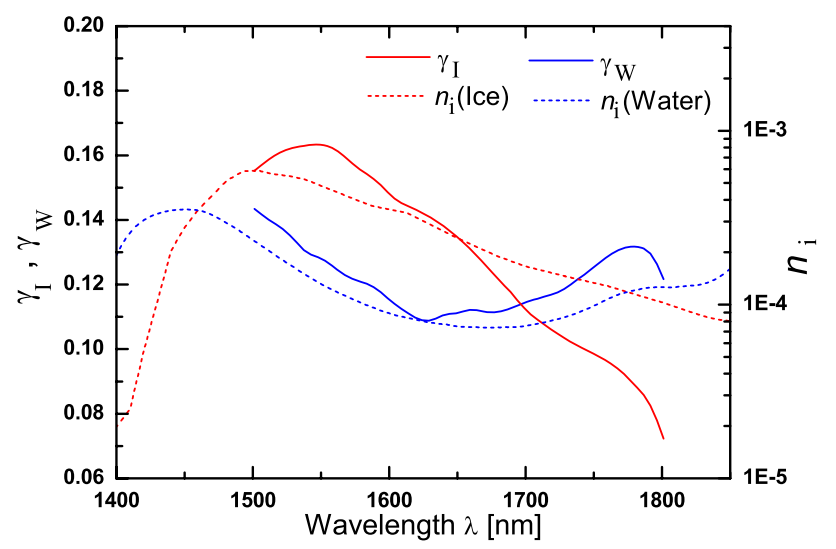

Fig. 6. Component weightings $\gamma_{\mathrm{I}}$ and $\gamma_{\mathrm{W}}$ for the calculation of the principle components $P C_{\mathrm{I}}$ and $P C_{\mathrm{W}}$ (solid lines). Dashed lines represent the imaginary part $n_{\mathrm{i}}$ of refractive index for ice and liquid water published by Warren (1984) and Wieliczka et al. (1989).

by applying the component weightings $\gamma_{i}$ obtained from the PCA as

$P C_{i}=\sum_{\lambda=\lambda_{1}}^{\lambda_{2}} \gamma_{i, \lambda} \frac{R_{\lambda}}{R_{860}} \quad i=1 \ldots \mathrm{N}$,

with $i$ defining the order of the principle component and $\mathrm{N}$ the number of wavelength channels used in the analysis. Due to the normalization by $R_{860}$ the remaining variance of the data will mainly result from changes in the absorption of the particles which are due to the variation of their effective diameter. Consequently the calculations show that the first principle component derived from the pure liquid water cloud simulations is related to liquid water absorption (hereinafter called $P C_{\mathrm{W}}$ ). The contribution of $R_{\lambda}$ at individual wavelengths to $P C_{\mathrm{W}}$ is given by the component weightings $\gamma_{\mathrm{W}}$ shown in Fig. 6 . The minimum weight occurs in the wavelengths between $1600 \mathrm{~nm}$ and $1700 \mathrm{~nm}$ where liquid water absorption is weak as indicated by the imaginary part $n_{\mathrm{i}}$ of the refractive index (dashed line). In the same way the first principle component from the pure ice cloud simulations (hereinafter called $P C_{\mathrm{I}}$ ) is correlated with ice absorption and has the maximum component weighting $\gamma_{\mathrm{I}}$ at wavelengths around $1550 \mathrm{~nm}$. In order to utilize $P C_{\mathrm{W}}$ and $P C_{\mathrm{I}}$ for cloud phase identification, we define a so called PCA ice index $I_{\mathrm{P}}$ as,

$I_{\mathrm{P}}=\left(\frac{P C_{\mathrm{I}}}{P C_{\mathrm{W}}}-0.94\right) \cdot 100$.

The offset of 0.94 has been determined arbitrarily in order to obtain values close to zero for liquid water clouds. For the observed liquid water cloud presented in Fig. $3 \mathrm{a}, I_{\mathrm{P}}=0.1$ was calculated. Values for all three observed clouds are given in Table 1. The results of the analysis of the simulated liquid water clouds shown in Fig. 7 reveal typical values of

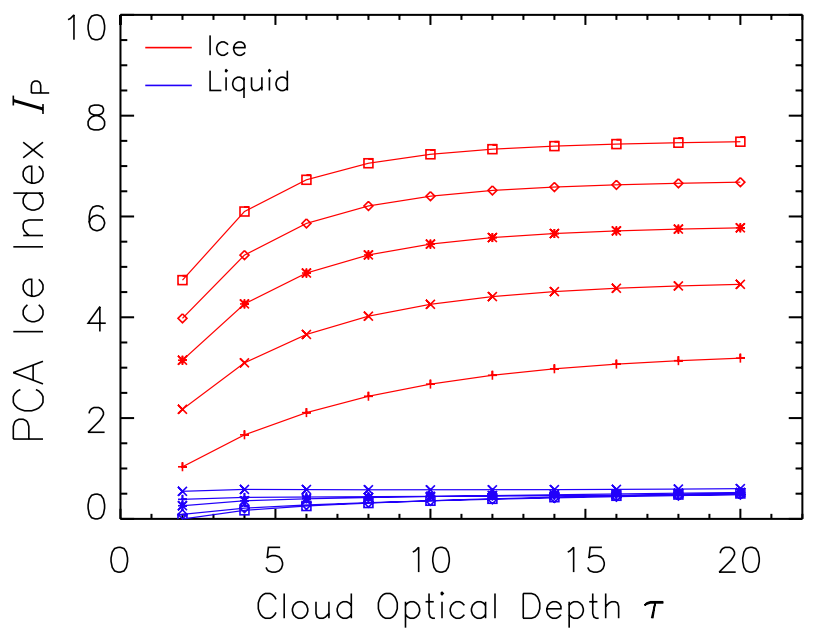

Fig. 7. Same as Fig. 5 for the PCA ice index $I_{\mathrm{P}}$.

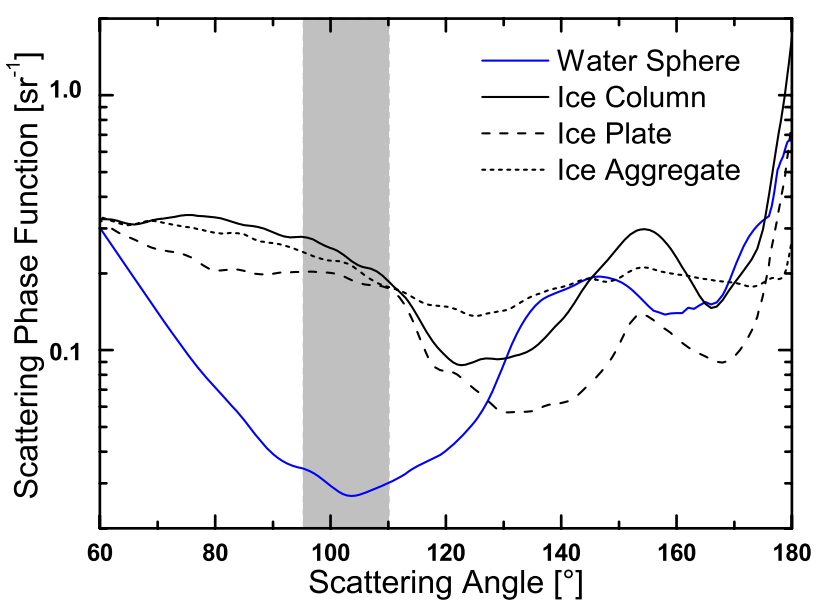

Fig. 8. Scattering phase function of different individual cloud particles at $640 \mathrm{~nm}$ wavelength. The diameter of the liquid water sphere is $16 \mu \mathrm{m}$. All ice crystals have a maximum dimension of $55 \mu \mathrm{m}$.

$I_{\mathrm{P}}=0-1$. For ice clouds $I_{\mathrm{P}}$ ranges from values of 1 up to 8 clearly capable of being distinguished from liquid water clouds. Therefore, $I_{\mathrm{P}}$ is a useful criterium to distinguish ice and liquid water clouds.

\subsection{Anisotropy ice index}

In general clouds act as non-lambertian reflectors. The radiance field reflected from cloud top is essentially affected by the anisotropic scattering phase function of the cloud particles. Representative scattering phase functions for spherical liquid water particles and ice crystals of column, plate and aggregate shape are illustrated in Fig. 8. Chepfer et al. (2002) used this information to retrieve the ice crystal shape from dual satellite measurements at the wavelength of $650 \mathrm{~nm}$. From the differences in the radiation scattered close to the 


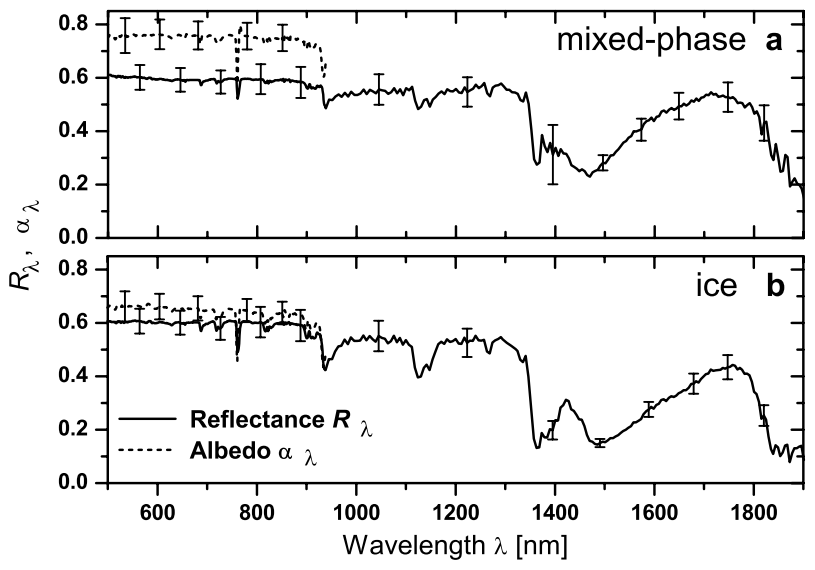

Fig. 9. Cloud top reflectance $R_{\lambda}$ and cloud albedo $\alpha_{\lambda}$ measured on 7 April 2007, above a mixed-phase cloud (a) of $\tau=15$ and a pure ice cloud (b) of $\tau=12$ introduced in Sect. 3.4 and Fig. 3.

backscatter angle of $180^{\circ}$ and those scattered into viewing angles between $60^{\circ}$ and $150^{\circ}$ particle phase and shape can be distinguished. A similar retrieval of particle phase and shape was applied by McFarlane et al. (2005) to measurements of the Multiangle Imaging Spectroradiometer (MISR) using the nine different viewing angles of the instrument. By minimizing the differences between measured and simulated reflectances they were able to calculate an ice index. It was shown that the highest differences between droplets and crystals occur at scattering angles between $70^{\circ}$ and $130^{\circ}$. Both studies emphasize that the retrieved properties are representative only for particles near cloud top.

The configuration of the SMART-Albedometer operating under conditions of low Sun allows for a similar retrieval of the cloud phase using simultaneous albedo and nadir reflectance measurements. With the high solar zenith angles $\left(70^{\circ}\right.$ to $\left.85^{\circ}\right)$ during ASTAR 2007, the nadir reflectance measurements correspond to side scattering by the cloud particles with scattering angles of $95^{\circ}$ to $110^{\circ}$ assuming single scattering as being predominant. As indicated by the grey area in Fig. 8 these scattering angles provide substantially enhanced scattering by nonspherical particles compared to spherical particles. This increases the upwelling radiance and cloud reflectance which is confirmed by simulations for $\theta=71^{\circ}$ shown in Fig. 4. The pure ice cloud shows higher $R_{\lambda}$ at wavelengths up to $1300 \mathrm{~nm}$ than the simulations for the pure liquid water cloud. On the other hand, the upwelling irradiance and consequently the albedo $\alpha_{\lambda}=F_{\lambda}^{\uparrow} / F_{\lambda}^{\downarrow}$ includes information from all scattering angles and is less dependent on the scattering phase function. This is illustrated in Fig. 9 by comparison of $R_{\lambda}$ and $\alpha_{\lambda}$ measured above the mixedphase and pure ice clouds observed on 7 April 2007. Both clouds were observed for $\theta=71^{\circ}$ and had a comparable optical thickness of 12 . The measurements show, that the dif-

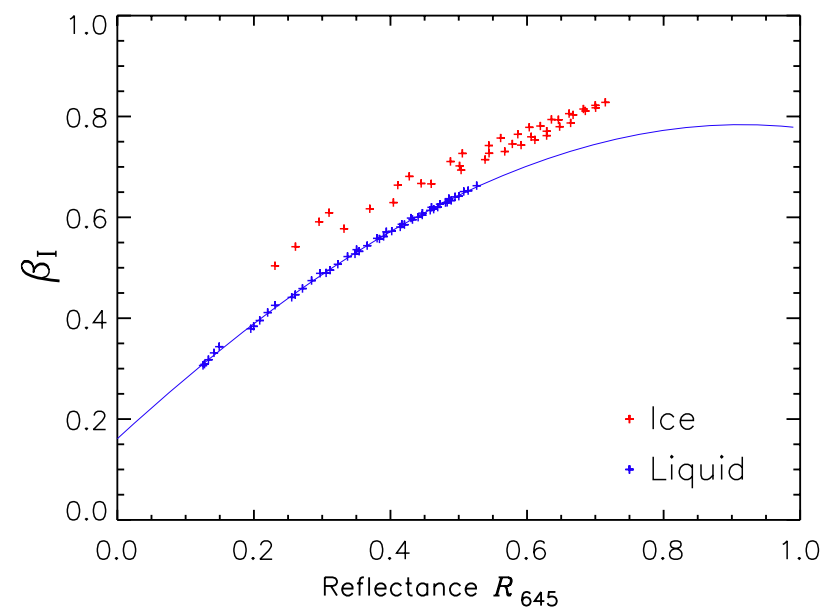

Fig. 10. Simulated $\beta_{\mathrm{I}}$ for pure liquid water clouds and pure ice clouds (column-shaped crystals) of different optical thickness $(\tau=2-20)$ and effective diameter (8-26 $\mu \mathrm{m}$ for liquid water and $10-100 \mu \mathrm{m}$ for ice clouds). The polynomial fit for the liquid water cloud is overlaid as a solid line $\left(\beta_{\mathrm{I}}=0.15+1.32 \cdot R_{\lambda}-0.67 \cdot R_{\lambda}^{2}+0.01 \cdot R_{\lambda}^{3}\right)$.

ference between $R_{\lambda}$ and $\alpha_{\lambda}$ is smaller for the ice cloud than for the mixed-phase cloud, where liquid water was found at cloud top.

Based on these findings, we suggest the ratio of cloud top reflectance and albedo at $645 \mathrm{~nm}$ wavelength $\beta_{\mathrm{I}}=R_{645} / \alpha_{645}$ as an indicator of the anisotropy of the radiation field reflected at cloud top. For the geometry presented here with $\theta=71^{\circ}, \beta_{\mathrm{I}}$ is always lower than 1 whereby nonspherical particles give a higher $\beta_{\mathrm{I}}$ than spherical particles. $\beta_{\mathrm{I}}=1$ would mean that the radiation is reflected isotropically, i.e., $\alpha=\pi R$.

With increasing cloud optical thickness both $\alpha$ and $R$ increase with a stronger increase for $R$. Increased multiple scattering diminishes the information of the scattering phase function and leads to more isotropically reflected radiation. That is why also $\beta_{\mathrm{I}}$ increases with cloud optical thickness. This relation is plotted in Fig. 10 using $R_{645}$ as a measure of cloud optical thickness on the abscissa. The data result from simulations of pure liquid water clouds and pure ice clouds presented above. Both liquid water and ice clouds show a distinct relation between $\beta_{\mathrm{I}}$ and $R_{645}$, with the isotropy of the reflected radiation being significantly higher above ice clouds than above liquid water clouds of the same $R_{645}$. These differences can be utilized to identify the cloud phase.

Therefore, we have parameterized $\beta_{\mathrm{I}}$ for the simulated liquid water clouds as function of $R_{645}$ by the polynomial fit shown as a blue solid line in Fig. 10. This parametrization is valid for the assumed geometry $(\theta$, nadir view, flight altitude) and the entire variety of liquid water clouds $\left(\tau, D_{\text {eff }}\right)$ provided by the simulation. This leads us to the definition of the anisotropy ice index $I_{\mathrm{A}}$ as the deviation of the measured $\beta_{\mathrm{I}}^{\text {meas }}$ from the $\beta_{\mathrm{I}}^{\text {water }}$ parameterized for liquid water clouds. 
$I_{\mathrm{A}}$ is calculated as the ratio

$I_{\mathrm{A}}=\frac{\beta_{\mathrm{I}}^{\text {meas }}}{\beta_{\mathrm{I}}^{\text {water }}}$.

Therefore, $\beta_{\mathrm{I}}^{\text {water }}$ is obtained from the polynomial fit using the measured value of $R_{645}^{\text {meas }}$. Using $R_{645}^{\text {meas }}$ incorporates indirectly the cloud optical thickness and reduces their impact on $I_{\mathrm{A}}$. From the definition of $I_{\mathrm{A}}$ it follows that we obtain $I_{\mathrm{A}}=1$ for pure liquid water clouds and $I_{\mathrm{A}}>1$ for pure ice clouds.

The results for the observed pure ice cloud and mixedphase cloud shown in Fig. 3a are given in Table 1. Both values differ significantly from unity. For the pure liquid water cloud it was not possible to calculate $I_{\mathrm{A}}$. This cloud had a small horizontal extension. The measured albedo was substantially affected by the dark water surface visible apart the cloud.

Typical values for water clouds obtained from the simulated clouds are shown in Fig. 11 and range between $I_{\mathrm{A}}=0.98$ and $I_{\mathrm{A}}=1.03$. Ice clouds give higher values of $I_{\mathrm{A}}>1.06$ separated distinctly from the results for liquid water clouds.

\section{Sensitivity studies}

The cloud top reflection (especially in the wavelength range used to calculate the ice indices) is affected not only by the cloud thermodynamic phase but also by other cloud optical properties (cloud optical thickness and cloud particle effective diameter). In order to reduce their impact on the cloud phase retrieval we apply different normalizations of $R_{\lambda}$ before calculating the ice indices as shown above. Nevertheless it is impossible to overcome those related uncertainties completely.

Acarreta et al. (2004) have shown for their ice index similar to the spectral slope ice index $I_{\mathrm{S}}$ that the obtained values for ice clouds may vary by a factor of up to 3 between clouds of small effective diameter/low cloud optical thickness and clouds of large effective diameter/high cloud optical thickness. Changes in the solar zenith angle have been found to be less important for the simulated ice indices. Especially for optically thin clouds the surface properties will have an impact on the ice indices. The surface albedo is crucial for the visible wavelength used to calculate the anisotropy ice index $I_{\mathrm{A}}$ while absorption by liquid water, snow or sea ice may affect the spectral slope ice index $I_{\mathrm{S}}$ and the PCA ice index $I_{\mathrm{P}}$. In order to reduce the complexity in this study we concentrate on the conditions found during ASTAR 2007 with an open sea surface.

In the following we discuss the impact of cloud optical thickness and particle effective diameter on the unambiguousness to discriminate pure ice and pure liquid water clouds by the ice indices defined in this paper (Sect. 5.1). Section 5.2 presents investigations of the sensitivity of the ice indices on the vertical structure of mixed-phase clouds.

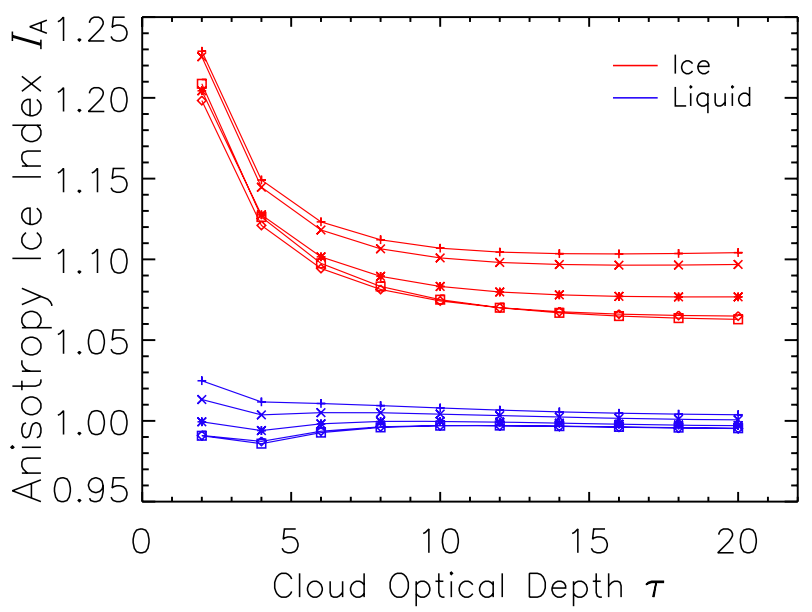

Fig. 11. Same as Fig. 5 for the anisotropy ice index $I_{\mathrm{A}}$.

\subsection{Cloud optical properties}

The ice indices $I_{\mathrm{S}}, I_{\mathrm{P}}$ and $I_{\mathrm{A}}$ calculated from the simulations of pure ice and liquid water clouds of different $\tau$ and $D_{\text {eff }}$ are shown in Figs. 5, 7 and 11. The plots reveal that the ice indices are almost insensitive to $D_{\text {eff }}$ and $\tau$ for pure liquid water clouds. The values vary only slightly with $D_{\text {eff }}$ and $\tau$. The spectral slope ice index $I_{\mathrm{S}}$ and the PCA ice index $I_{\mathrm{P}}$ show almost no variation with $\tau$. On the other hand, the ice indices of the pure ice clouds spread over a wide range. Most significant is the decrease of $I_{\mathrm{S}}$ and $I_{\mathrm{P}}$ with decreasing $D_{\text {eff. }}$. Especially for optically thin ice clouds $I_{\mathrm{S}}$ can reach values of pure liquid water clouds with high optical thickness. A slight improvement is given by $I_{\mathrm{P}}$. Here none of the ice clouds gives values as low as the simulated liquid water clouds. The discrimination of pure ice and pure liquid water clouds is almost unambiguous. With regard to an identification of mixed-phase clouds a priori knowledge of $D_{\text {eff }}$ and $\tau$ is needed. The ice indices obtained for a mixed-phase cloud range between a minimum value given by a liquid water cloud and a maximum given by an ice cloud with $D_{\text {eff }}$ and $\tau$ equal to the values of the mixed-phase cloud (not shown here). If $D_{\text {eff }} \tau$ and accordingly the maximum values of $I_{\mathrm{S}}$ and $I_{\mathrm{P}}$ are not known, the ice indices obtained for the mixedphase cloud may indicate a pure ice cloud with smaller $D_{\text {eff }}$ or smaller $\tau$.

Most robust with regard to the cloud optical properties of ice crystals is the anisotropy ice index $I_{\mathrm{A}}$. Figure 11 shows that values for ice and liquid water clouds differ for all simulations. Therefore $I_{\mathrm{A}}$ is most suitable for discriminating ice and liquid water clouds in the setting of the present sensitivity study. It has to be pointed out that theoretically $I_{\mathrm{A}}$ is exactly 1 for the liquid water clouds as the data shown here are simulations equal to the simulations used to parameterize $\beta_{\mathrm{I}}^{\text {water }}$. The deviation from 1 results from slight differences between data points of $\beta_{\mathrm{I}}^{\text {water }}$ and its parameterization (cp. Fig. 10). 
Table 2. $I_{\mathrm{S}}, I_{\mathrm{P}}$, and $I_{\mathrm{A}}$ of mixed-phase clouds $\left(\tau_{\mathrm{W}}=13.5, \tau_{\mathrm{I}}=1.5\right)$ for different positions of the ice layer (not all 10 simulations shown here). The position is given by the optical thickness $\tau_{\mathrm{W}}^{\text {top }}$ of the liquid water layer above the single ice layer.

\begin{tabular}{cccc}
\hline$\tau_{\mathrm{W}}^{\text {top }}$ & $I_{\mathrm{S}}$ & $I_{\mathrm{P}}$ & $I_{\mathrm{A}}$ \\
\hline 0.0 & 41.0 & 3.3 & 1.08 \\
1.5 & 32.2 & 2.4 & 1.01 \\
3.0 & 25.7 & 1.8 & 1.00 \\
6.0 & 18.4 & 1.2 & 1.00 \\
9.0 & 14.6 & 0.8 & 1.00 \\
13.5 & 11.8 & 0.5 & 1.00
\end{tabular}

\subsection{Vertical distribution}

Generally, the definition of a mixed-phase cloud is that ice and liquid water particles coexist in a certain cloud volume. For radiative transfer simulations there are different options to realize this mixture, either as a homogeneous mixed single-layer cloud or as a multi-layer cloud with distinct pure ice and liquid water layers. From the in situ measurements presented in Sect. 3.2 it follows that boundary-layer mixedphase clouds typically consist of two layers with liquid water droplets at cloud top and precipitating ice below. In this sensitivity study we focus on the ability to identify such mixedphase clouds and how the layering affects the cloud phase retrieval.

Radiative transfer simulations have been performed based on the microphysical measurements on 7 April 2007, presented in Sect. 3. The cloud optical properties were fixed at $\tau=15, D_{\text {eff }}=15 \mu \mathrm{m}$ for liquid water particles and $D_{\text {eff }}=85 \mu \mathrm{m}$ for ice particles. The cloud was divided into 10 sublayers with a homogeneous liquid water mode of $\tau_{\mathrm{W}}=1.5$ for each layer. One ice layer $\left(\tau_{I}=1.5\right)$ was added and shifted from cloud top to cloud bottom. For each simulation the ice indices $I_{\mathrm{S}}, I_{\mathrm{P}}$ and $I_{\mathrm{A}}$ were calculated. The results are given in Table 2.

The results show that all three indices are most sensitive to the upper cloud layer showing the highest values if the ice layer is located at cloud top $\left(\tau_{\mathrm{W}}^{\text {top }}=0\right)$. Here $\tau_{\mathrm{W}}^{\text {top }}$ gives the total optical thickness of the liquid water layers located above the single ice layer. The maximum values of $I_{\mathrm{S}}=41, I_{\mathrm{P}}=3.3$ and $I_{\mathrm{A}}=1.08$ range above typical values for pure liquid water clouds and below the maximum values of an ice cloud with equal $D_{\text {eff }}=85 \mu \mathrm{m}$ and $\tau=15$ as used in the simulations of the mixed-phase cloud (cf. Fig. 5, 7 and 11). The spectral slope ice index $I_{\mathrm{S}}$ and the PCA ice index $I_{\mathrm{P}}$ decrease slowly with increasing $\tau_{\mathrm{W}}^{\text {top }}$ to values of $I_{\mathrm{S}}=12, I_{\mathrm{P}}=0.5$ which reaches the range simulated for pure water clouds. Nevertheless, for $\tau_{\mathrm{W}}^{\text {top }}<10$ and considering the effective diameter of the water particles $\left(D_{\text {eff }}=15 \mu \mathrm{m}\right)$ the ice indices $I_{\mathrm{S}}$ and $I_{\mathrm{P}}$ are higher than for pure liquid water clouds. This suggests that these approaches are able to dis- tinguish typical boundary-layer mixed-phase clouds with a liquid cloud top layer from pure liquid water clouds. It has to be pointed out that the sensitivity of $I_{S}$ and $I_{P}$ to mixedphase clouds will be reduced if a smaller $D_{\text {eff }}$ of the ice crystals is assumed. Smaller ice crystals have less absorption which results in reduced differences of $I_{S}$ and $I_{P}$ between pure ice and liquid water clouds (cp. Figs. 5 and 7).

The anisotropy ice index $I_{\mathrm{A}}$ deviates from the values of pure liquid water clouds only if the ice layer is at cloud top. This suggests that $I_{\mathrm{A}}$ is suitable only for a discrimination of pure ice and pure liquid water clouds. Typical boundarylayer mixed-phase clouds with liquid cloud top will be identified as pure liquid water clouds. This is consistent with the findings of Chepfer et al. (2002) who found that the particle shape retrieved from two scattering angles at $650 \mathrm{~nm}$ wavelength was insensitive to multilayered clouds when $\tau$ of the cloud top layer is larger than 2 .

\section{Case study on 7 April 2007}

On 7 April 2007, concurrent radiation and microphysical measurements were conducted along the path of the CloudAerosol Lidar and Infrared Pathfinder Satellite (CALIPSO) over the Greenland Sea as marked in Fig. 1 with B. A stratus cloud field with cloud top up to $1500 \mathrm{~m}$ extended from $77.3^{\circ} \mathrm{N}$ to northwards at the time of the CALIPSO overpass (10:18 UTC). The profile of the total attenuated backscatter signal measured by CALIPSO is shown in Fig. 12a. The lidar could not completely penetrate the optically thick clouds with exception of the cloud edge $\left(<77.4^{\circ} \mathrm{N}\right)$. For the investigated cloud the depolarization measurements (not shown here) are not suitable for a cloud phase analysis. Multiple scattering in the optically thick clouds increased the depolarization regardless of particle shape. Nevertheless, the lidar profiles reveal that in the southern part of the cloud deck (see Fig. 1 and left-side of Fig. 12a) ice particles are precipitating down to the surface. These precipitation particles, which are also observed from CloudSat (reflectivity), can be detected by the Lidar because they are not capped by a liquid water layer in this area.

This part of the cloud was sampled with in situ microphysical instruments about 1 hour before the CALIPSO overpass. Considering the advection of the cloud field with the northerly winds the measurements showed that the cloud edge in the southern part consisted of ice particles only (Fig. $12 \mathrm{~b},<77.4^{\circ} \mathrm{N}$ ). The particle concentration measured by the CPI increases up to $N_{\text {tot }}=3 \mathrm{~cm}^{-3}$. First liquid water particles were observed with the FSSP $3 \mathrm{~km}$ further north. After the descent below the cloud base $\left(77.5^{\circ} \mathrm{N}\right.$ to $\left.77.6^{\circ} \mathrm{N}\right)$ the partly high ice crystal concentrations with simultaneous absence of liquid water particles is related again to precipitating ice below the cloud. Higher cloud layers are probably of mixed-phase as measured during the ascent through the cloud $\left(77.6^{\circ} \mathrm{N}\right.$ to $\left.77.7^{\circ} \mathrm{N}\right)$. 


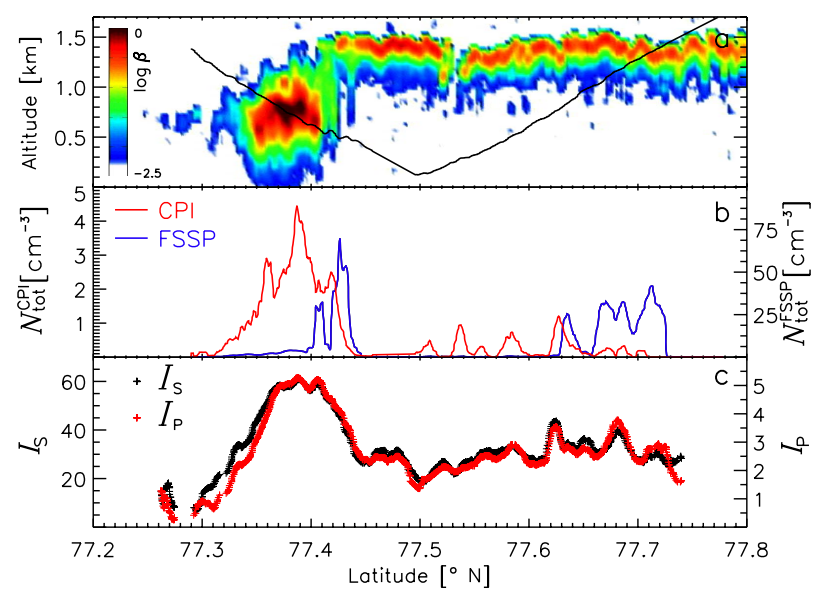

Fig. 12. Profile of total attenuated backscatter coefficient $\beta\left[\mathrm{sr}^{-1} \mathrm{~km}^{-1}\right]$ measured by CALIPSO in the cloud observed on 7 April 2007 (a). The flight track of the in situ measurements is overlaid as a black line. Ice and liquid water particle concentrations $N_{\text {tot }}$ measured by CPI and FSSP along the flight track and the ice indices $I_{\mathrm{S}}$ and $I_{\mathrm{P}}$ for the same positions are given in panel $\mathrm{b}$ and $\mathrm{c}$.

Shortly after the CALIPSO overpass the cloud was investigated again by radiation measurements flying above the cloud top. From the measured cloud top reflectance the cloud phase was remotely identified using the ice indices defined above. Figure 12c shows the measured spectral slope ice index $I_{\mathrm{S}}$ and PCA ice index $I_{\mathrm{P}}$ along the flight track of 7 April 2007. Both ice indices show high values around $77.4^{\circ} \mathrm{N}$ which correlates with the high ice particle concentration measured by the in situ instrumentation one hour earlier. The maximum values of $I_{\mathrm{S}}=60$ and $I_{\mathrm{P}}=5$ indicate a pure ice cloud when compared to the simulations shown in Fig. 5. With measured values of $D_{\text {eff }}=85 \mu \mathrm{m}$ and $\tau=15$, the simulations for $D_{\text {eff }}=90 \mu \mathrm{m}$ and $\tau=15$ show values of $I_{\mathrm{S}}$ and $I_{\mathrm{P}}$ similar to the ice indices calculated from the measurements.

Lower values $\left(I_{\mathrm{S}}=20-40\right.$ and $\left.I_{\mathrm{P}}=2-4\right)$ corresponding to mixed-phase clouds assuming unchanged $D_{\text {eff }}$ and $\tau$ were measured later when the FSSP measured significant liquid water particle concentrations. With respect to the sensitivity studies of Sect. 5, $I_{\mathrm{S}}$ and $I_{\mathrm{P}}$ measured above the mixed-phase clouds are higher than expected and close to values of pure ice clouds with small effective diameter. This reveals that either the fraction of ice crystals is much higher than measured by the in situ measurements or the vertical distribution of the ice differs from the assumption of a liquid cloud top layer with high ice concentrations below.

The analysis of the reflectance-albedo ratio $\beta_{\mathrm{I}}$ also reveals the presence of ice at the cloud edge. Figure 13 shows all measurements taken on 7 April 2007, above clouds $\left(\theta=71^{\circ}\right)$. Generally the measured values of $\beta_{\mathrm{I}}$ deviate from the theoretical curve of pure liquid water clouds (1-D simulations) which is not expected for mixed-phase clouds with a thick liquid layer at cloud top (cp. Sect. 5.2). The high values of $\beta_{\mathrm{I}}$

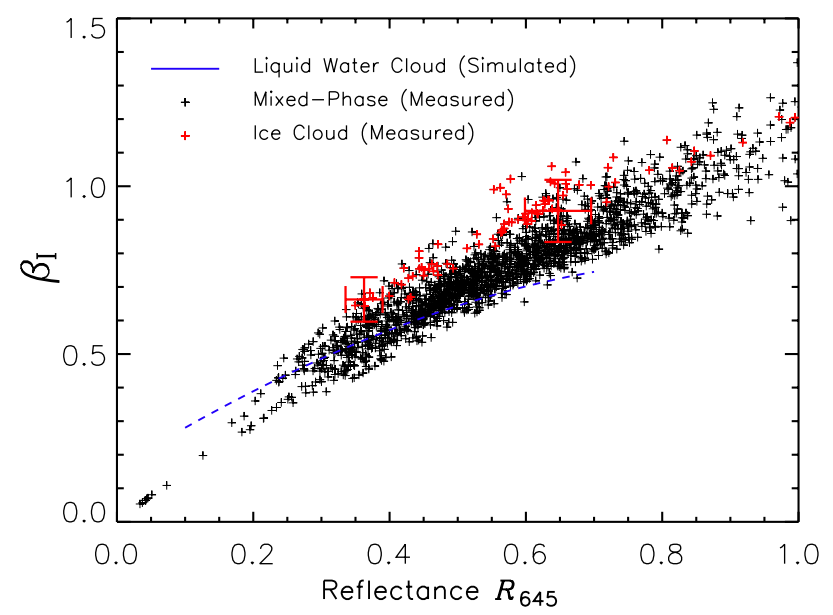

Fig. 13. Measured $\beta_{\mathrm{I}}$ as function of $R_{645}$. Black crosses show measurements over mixed-phase clouds, red crosses over the ice cloud observed on the cloud edge. Simulations for pure liquid water clouds are shown as a blue line.

indicate the presence of ice crystals at the top of the mixedphase clouds. It has to be pointed out here that due to the combination of three separate measurements $\left(F_{\lambda}^{\downarrow}, F_{\lambda}^{\uparrow}\right.$ and $I_{\lambda}^{\uparrow}$ ) the uncertainties of the data points are relatively high as marked at two measurements samples in Fig. 13. Furthermore, the 1-D simulations used to define the anisotropy ice index $I_{\mathrm{A}}$ do not account for possible 3-D radiative effects. Nevertheless the measurements above the cloud edge (labeled by red crosses) tend to range in higher values of $\beta_{\mathrm{I}}$. This shows that at the cloud edge nonspherical ice crystals were present at cloud top.

\section{Conclusions}

Three different methods to derive the cloud thermodynamic phase from airborne spectral solar radiation measurements are presented. The ice index $I_{\mathrm{S}}$ analyzing the slope of the spectral reflectance and the ice index $I_{\mathrm{P}}$ obtained from PCA are capable to identify the cloud phase of Arctic boundarylayer clouds observed during ASTAR 2007. In a case study a pure ice cloud at the edge of a mixed-phase cloud field also probed by in situ microphysical probes and observed by CALIPSO shows significantly higher values of $I_{S}$ and $I_{\mathrm{P}}$ related to ice particles. The mixed-phase clouds inside the cloud field have lower ice indices than the ice cloud but higher values than expected for pure liquid water clouds.

A third ice index $I_{\mathrm{A}}$ based on the anisotropy of the reflected radiation and defined by the ratio between cloud reflectance and albedo is not able to detect mixed-phase clouds. Simulations show that $I_{\mathrm{A}}$ is mainly affected by the uppermost cloud layers. The optical thickness of the relevant cloud layer was found to be less than $\tau<1.5$. Therefore, mixed-phase 
clouds with liquid cloud top will be identified as pure liquid clouds. Nevertheless, for the edge of the cloud field the presence of nonspherical ice crystals is confirmed.

At least for the cloud top layer the anisotropy ice index $I_{\mathrm{A}}$ is theoretically a more robust indicator for the cloud phase than the spectral slope ice index $I_{\mathrm{S}}$ and the PCA ice index $I_{\mathrm{P}}$. Sensitivity studies have shown that both indices $I_{\mathrm{S}}$ and $I_{\mathrm{P}}$ are strongly dependent on the ice particle effective diameter and less dependent on cloud optical thickness for $\tau<5$. Nevertheless, an ambiguity in the discrimination of ice and liquid water phase occurs only between pure ice clouds with small ice crystals and low $\tau$ and pure liquid water clouds of high $\tau$. More crucial is the dependence on the ice particle effective diameter for the discrimination between mixed-phase and pure ice clouds. Here, a priori knowledge about the ice crystal dimensions is required.

The case study has shown, that the anisotropy ice index $I_{\mathrm{A}}$ is more difficult to interpret than $I_{\mathrm{S}}$ and $I_{\mathrm{P}}$. The combination of three independent measurements and possible 3-D radiative effects result in a higher uncertainty of this method. From a single measuring point the retrieval of the cloud phase is not reliable. Cluster analysis or averaging is necessary.

Considering the advantages and uncertainties of all three methods, we suggest to rely on a combination of the methods in further studies. Together with airborne lidar and in situ microphysical measurements such as presented here, further investigations will help to verify algorithms for cloud phase identification from satellites (CALIPSO, CloudSat, MODIS). Especially airborne hyperspectral camera systems resolving the near infrared wavelength range will be capable of investigating the detailed horizontal distribution of ice and liquid water particles.

Acknowledgements. This research was funded by the German Research Foundation (DFG, WE 1900/8-1) and AWI. We thank Ping Yang, Department of Atmospheric Sciences at Texas A\&M University, for providing the library of optical properties of ice crystals used in our simulations. Bernhard Mayer (Institute of Atmospheric Physics, German Aerospace Center) is thanked for his support with the libRadtran package. The CALIPSO data presented here are courtesy of the NASA Langley Research Center Atmospheric Science Data Center. For the technical support during the ASTAR campaign we want to acknowledge the companies enviscope $\mathrm{GmbH}$ and OPTIMARE GmbH.

Edited by: T. Garrett

\section{References}

Acarreta, J. R., Stammes, P., and Knap, W. H.: First retrieval of cloud phase from SCIAMACHY spectra around $1.6 \mu \mathrm{m}$, Atmos. Res., 72, 89-105, 2004.

Bierwirth, E., Wendisch, M., Ehrlich, A., Heese, B., Tesche, M., Althausen, D., Schladitz, A., Müller, D., Otto, S., Trautmann, T., Dinter, T., von Hoyningen-Huene, W., and Kahn, R.: Spec- tral surface albedo over Morocco and its impact on the radiative forcing of Saharan dust, Tellus, accepted, 2008.

Boudala, F. S., Isaac, G. A., Cober, S. G., and Fu, Q.: Liquid fraction in stratiform mixed-phase clouds from in situ observations, Quart. J. Roy. Meteor. Soc., 130, 2919-2931, 2004.

Buriez, J., Vanbauce, C., Parol, F., Goloub, P., Herman, M., Bonnel, B., Fouquart, Y., Couvert, P., and Seze, G.: Cloud detection and derivation of cloud properties from POLDER, Int. J. Remote Sensing, 18, 2785-2813, 1997.

Chepfer, H., Minnis, P., Young, D., Nguyen, L., and Arduini, R. F.: Estimation of cirrus cloud effective ice crystal shapes using visible reflectances from dual-satellite measurements, J. Geophys. Res-Atmos., 107, 4730, doi:10.1029/2000JD000240, 2002.

Chylek, P., Robinson, S., Dubey, M. K., King, M. D., Fu, Q., and Clodius, W. B.: Comparison of near-infrared and thermal infrared cloud phase detections, J. Geophys. Res-Atmos., 111, D20203, doi:10.1029/2006JD007140, 2006.

Cober, S. G., Isaac, G. A., Korolev, A. V., and Strapp, J. W.: Assessing cloud-phase conditions, J. Appl. Meteor., 40, 1967-1983, 2001.

Corell, R.: Arctic Climate Impact Assessment, Cambridge University Press, Cambridge, UK, 2004.

Crowther, B.: The Design, Construction, and Calibration of a Spectral Diffuse/Global Irradiance Meter, Ph.D. thesis, University of Arizona, 1997.

Curry, J. A., Rossow, W. B., Randall, D., and Schramm, J. L.: Overview of Arctic cloud and radiation characteristics, J. Climate, 9, 1731-1764, 1996.

Dong, X. Q. and Mace, G. G.: Arctic stratus cloud properties and radiative forcing derived from ground-based data collected at Barrow, Alaska, J. Climate, 16, 445-461, 2003.

Ehrlich, A., Bierwirth, E., Wendisch, M., Gayet, J.-F., Mioche, G., and Richter, A.: Cloud phase identification over Arctic mixedphase clouds from airborne spectral cloud top reflectance measurements, in: Proceedings of the ICCP Conference, Cancun, Mexico, 7-11 July, 2008a.

Ehrlich, A., Wendisch, M., Bierwirth, E., Herber, A., and Schwarzenböck, A.: Ice crystal shape effects on solar radiative properties of Arctic mixed-phase clouds - Dependence on microphysical properties, Atmos. Res., 88, 266-276, 2008b.

Freese, D. and Kottmeier, C.: Radiation exchange between stratus clouds and polar marine surfaces, Bound.-Lay. Meteor., 87, 331356, 1998.

Fridlind, A. M., Ackerman, A. S., McFarquhar, G., Zhang, G., Poellot, M. R., DeMott, P. J., Prenni, A. J., and Heymsfield, A. J.: Ice properties of single-layer stratocumulus during the Mixed-Phase Arctic Cloud Experiment: 2. Model results, J. Geophys. Res.Atmos., 112, D24202, doi:10.1029/2007JD008646, 2007.

Garrett, T. J., Hobbs, P. V., and Gerber, H.: Shortwave, singlescattering properties of arctic ice clouds, J. Geophys. ResAtmos., 106, 15 155-15 172, 2001.

Gayet, J.-F., Stachlewska, I. S., Jourdan, O., Shcherbakov, V., Schwarzenboeck, A., and Neuber, R.: Microphysical and optical properties of precipitating drizzle and ice particles obtained from alternated Lidar and in situ measurements, Ann. Geophys., 25, 1487-1497, 2007, http://www.ann-geophys.net/25/1487/2007/.

Gerber, H., Takano, Y., Garrett, T. J., and Hobbs, P. V.: Nephelometer measurements of the asymmetry parameter, volume extinc- 
tion coefficient, and backscatter ratio in Arctic clouds, J. Atmos. Sci., 57, 3021-3034, 2000.

Harrington, J. Y., Reisin, T., Cotton, W. R., and Kreidenweis, S. M.: Cloud resolving simulations of Arctic stratus - Part II: Transition-season clouds, Atmos. Res., 51, 45-75, 1999.

Hu, Y., Vaughan, M., Liu, Z., Lin, B., Yang, P., Flittner, D., Hunt, B., Kuehn, R., Huang, J., Wu, D., Rodier, S., Powell, K., Trepte, C., and Winker, D.: The depolarization attenuated backscatter relation: CALIPSO lidar measurements vs. theory, Optics Express, 15, 5327-5332, 2007.

Intrieri, J. M., Fairall, C. W., Shupe, M. D., Persson, P. O. G., Andreas, E. L., Guest, P. S., and Moritz, R. E.: An annual cycle of Arctic surface cloud forcing at SHEBA, J. Geophys. Res.Oceans, 107, 8039, doi:10.1029/2000JC000439, 2002.

Jäkel, E., Wendisch, M., Kniffka, A., and Trautmann, T.: Airborne system for fast measurements of upwelling and downwelling spectral actinic flux densities, Appl.Opt., 44, 434-444, 2005.

Key, J. and Intrieri, J.: Cloud particle phase determination with the AVHRR, J. Appl. Meteorol., 39, 1797-1804, 2000.

King, M. D., Platnick, S., Yang, P., Arnold, G. T., Gray, M. A., Riedi, J. C., Ackerman, S. A., and Liou, K. N.: Remote sensing of liquid water and ice cloud optical thickness and effective radius in the Arctic: Application of airborne multispectral MAS data, J. Atmos. Oceanic Technol., 21, 857-875, 2004.

Knap, W., Stammes, P., and Koelemeijer, R.: Cloud thermodynamic-phase determination from near-infrared spectra of reflected sunlight, J. Atmos. Sci., 59, 83-96, 2002.

Kokhanovsky, A. A., von Hoyningen-Huene, W., Rozanov, V. V., Noël, S., Gerilowski, K., Bovensmann, H., Bramstedt, K., Buchwitz, M., and Burrows, J. P.: The semianalytical cloud retrieval algorithm for SCIAMACHY II. The application to MERIS and SCIAMACHY data, Atmos. Chem. Phys., 6, 4129-4136, 2006, http://www.atmos-chem-phys.net/6/4129/2006/.

Korolev, A. V., Isaac, G. A., Cober, S. G., Strapp, J. W., and Hallett, J.: Microphysical characterization of mixed-phase clouds, Quart. J. Roy. Meteor. Soc., 129, 39-65, 2003.

Lawson, R. P., Baker, B. A., Schmitt, C. G., and Jensen, T. L.: An overview of microphysical properties of Arctic clouds observed in May and July 1998 during FIRE ACE, J. Geophys. Res-Atmos., 106, 14 989-15 014, 2001.

Mayer, B. and Kylling, A.: Technical note: The libRadtran software package for radiative transfer calculations - description and examples of use, Atmos. Chem. Phys., 5, 1855-1877, 2005, http://www.atmos-chem-phys.net/5/1855/2005/.

McFarlane, S. A., Marchand, R. T., and Ackerman, T. P.: Retrieval of cloud phase and crystal habit from Multiangle Imaging Spectroradiometer (MISR) and Moderate Resolution Imaging Spectroradiometer (MODIS) data, J. Geophys. Res.-Atmos., 110, D14201, doi:10.1029/2004JD004831, 2005.

McFarquhar, G. M., Zhang, G., Poellot, M. R., Kok, G. L., Mccoy, R., Tooman, T., Fridlind, A., and Heymsfield, A. J.: Ice properties of single-layer stratocumulus during the Mixed-Phase Arctic Cloud Experiment: 1. Observations, J. Geophys. Res-Atmos., 112, D24201, doi:10.1029/2007JD008633, 2007.

Miles, N. L., Verlinde, J., and Clothiaux, E. E.: Cloud droplet size distributions in low-level stratiform clouds, J. Atmos. Sci., 57, 295-311, 2000.

Morrison, H., Pinto, J. O., Curry, J. A., and McFarquhar, G. M.: Sensitivity of modeled arctic mixed-phase stratocumu- lus to cloud condensation and ice nuclei over regionally varying surface conditions, J. Geophys. Res-Atmos., 113, D05203, doi:10.1029/2007JD008729, 2008.

Nakajima, T. and King, M.: Determination of the optical thickness and effective particle radius of clouds from reflected solar radiation measurements. Part I: Theory, J. Atmos. Sci., 47, 18781893, 1990.

Pearson, K.: On lines and planes of closest fit to systems of points in space, Philos. Mag., 2, 559-572, 1901.

Pilewskie, P. and Twomey, S.: Discrimination of ice from water in clouds by optical remote sensing, Atmos. Res., 21, 113-122, 1987.

Rabbette, M. and Pilewskie, P.: Multivariate analysis of solar spectral irradiance measurements, J. Geophys. Res-Atmos., 106, 9685-9696, 2001

Sassen, K. and Wang, Z.: Classifying clouds around the globe with the CloudSat radar: 1-year of results, Geophys. Res. Lett., 35, L04805, doi:10.1029/2007GL032591, 2008.

Shupe, M. D. and Intrieri, J. M.: Cloud radiative forcing of the Arctic surface: The influence of cloud properties, surface albedo, and solar zenith angle, J. Climate, 17, 616-628, 2004.

Stachlewska, I., Wehrle, G., Stein, B., and Neuber, R.: Airborne Mobile Aerosol Lidar for measurements of Arctic aerosols, Proceedings of 22nd International Laser Radar Conference (ILRC2004), ESA SP-561, 1, 87-89, 2004.

Stamnes, K., Tsay, S., Wiscombe, W., and Jayaweera, K.: A numerically stable algorithm for discrete-ordinate-method radiative transfer in multiple scattering and emitting layered media, Appl. Opt., 27, 2502-2509, 1988.

Sun, Z. and Shine, K. P.: Studies of the Radiative Properties of Ice and Mixed-Phase Clouds, Quart. J. Roy. Meteor. Soc., 120, 111 137, 1994.

Warren, S. G.: Optical-Constants Of Ice From The Ultraviolet To The Microwave, Appl. Opt., 23, 1206-1225, 1984.

Wendisch, M. and Mayer, B.: Vertical distribution of spectral solar irradiance in the cloudless sky: A case study, Geophys. Res. Lett., 30, 1183, doi:10.1029/2002GL016529, 2003.

Wendisch, M., Müller, D., Schell, D., and Heintzenberg, J.: An airborne spectral albedometer with active horizontal stabilization, J. Atmos. Oceanic Technol., 18, 1856-1866, 2001.

Wendisch, M., Pilewskie, P., Jäkel, E., Schmidt, S., Pommier, J., Howard, S., Jonsson, H. H., Guan, H., Schroder, M., and Mayer, B.: Airborne measurements of areal spectral surface albedo over different sea and land surfaces, J. Geophys. Res-Atmos., 109, D08203, doi:10.1029/2003JD004392, 2004.

Wieliczka, D. M., Weng, S. S., and Querry, M. R.: Wedge Shaped Cell For Highly Absorbent Liquids - Infrared Optical-Constants Of Water, Appl. Opt., 28, 1714-1719, 1989.

Yang, P. and Liou, K. N.: Finite-difference time domain method for light scattering by small ice crystals in three-dimensional space, J. Opt. Soc. Am. A., 13, 2072-2085, 1996.

Yoshida, Y. and Asano, S.: Effects of the vertical profiles of cloud droplets and ice particles on the visible and near-infrared radiative properties of mixed-phase stratocumulus clouds, J. Meteor. Soc. Japan, 83, 471-480, 2005. 